\title{
Germinação e vigor de sementes de mogno africano sob diferentes temperaturas
}

\author{
Germination and effect of african mahogany seeds under different temperatures
}

\author{
Rebeca Alves Nunes Silva ${ }^{\mathrm{I}}$, Andréia Márcia Santos de Souza David ${ }^{\mathrm{II}}$,

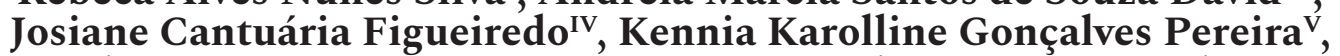 \\ Cristiane Alves Fogaça ${ }^{\mathrm{III}}$, Franson Ronner Pereira Alves ${ }^{\mathrm{I}}$, Larissa Medeiros Soares ${ }^{\mathrm{II}}$
}

\begin{abstract}
Resumo
O mogno africano é uma espécie arbórea muito valorizada pela indústria, pois sua madeira de alta qualidade possui grande potencial econômico tanto para o mercado interno quanto para o mercado externo. Apesar da alta valorização, os estudos e pesquisas sobre a espécie são escassos, sendo de extrema importância aprofundar o conhecimento. O objetivo do estudo foi avaliar o efeito de diferentes temperaturas sobre a germinação e vigor de sementes de mogno africano em condição de laboratório. O delineamento experimental utilizado foi o inteiramente casualizado, em esquema fatorial $4 \times 5$, sendo 4 lotes de sementes e cinco regimes de temperatura $\left(20,25,30,35^{\circ} \mathrm{C}\right.$ constantes e $20-30^{\circ} \mathrm{C}$ alternada), com quatro repetições de vinte e cinco sementes por tratamento. Inicialmente determinou-se o teor de água das sementes e em seguida realizou-se os seguintes testes: germinação, primeira contagem da germinação, comprimento, massa fresca e seca de plântulas. As temperaturas de 25 e $30^{\circ} \mathrm{C}$ constantes são favoráveis à germinação e ao vigor das sementes de mogno africano. Temperaturas de 20 e $35^{\circ} \mathrm{C}$ constante e $20-30^{\circ} \mathrm{C}$ alternadas são prejudiciais ao processo germinativo, comprometendo o desempenho fisiológico das sementes. Nas temperaturas favoráveis à germinação, as sementes dos lotes 1 e 3 mostraram-se com qualidade fisiológica superior aos demais.
\end{abstract}

Palavras-chave: Khaya grandifoliola; Qualidade fisiológica; Sementes florestais; Análise de sementes

\begin{abstract}
African mahogany is a tree species highly valued by industry because its high quality wood has great economic potential both for the domestic market and for the foreign market. Despite the high valuation, the studies and research on the species are scarce, being extremely important to deepen its knowledge. The objective of this work was to evaluate the effect of different temperatures on the germination and vigor of African mahogany seeds. The experimental design was a completely randomized design, in a $4 \times 5$ factorial scheme, with four seed lots and five temperature regimes $\left(20,25,30,35^{\circ} \mathrm{C}\right.$ constant and $20-30^{\circ} \mathrm{C}$ alternating), with four replications of twenty five seeds per treatment. Temperatures of 25 and $30^{\circ} \mathrm{C}$ are favorable to the germination and vigor of African mahogany seeds. Temperatures of 20 and $35^{\circ} \mathrm{C}$ constant and $20-30^{\circ} \mathrm{C}$ alternating are harmful to the germination process, compromising the physiological performance of the seeds. At temperatures favorable to germination, the seeds of lots 1 and 3 showed higher physiological quality than the others.
\end{abstract}

Keywords: Khaya grandifoliola; Physiological quality; Forest seeds; Seed analysis

Engenheiro(a) Agrônomo(a), Universidade Estadual de Montes Claros, Av. Reinaldo Viana, 2630, Bico da Pedra, CEP 39440-000, Janaúba(MG), Brasil. rebeca.nunnes@hotmail.com (ORCID: 0000-0002-2174-3503) / fransonagricola@gmail.com (ORCID: 0000-0002-8293-1540)

II Graduanda em Agronomia Departamento de Ciências Agrárias, Universidade Estadual de Montes Claros, Av. Reinaldo Viana, 2630, Bico da Pedra, CEP 39440-000, Janaúba (MG), Brasil. larimedeirosoares@gmail.com (ORCID: 0000-0002-1867-9440)

III Engenheira Agrônoma, Dra., Professora do Departamento de Ciências Agrárias, Universidade Estadual de Montes Claros, Av. Reinaldo Viana, 2630, Bico da Pedra, CEP 39440-000, Janaúba (MG), Brasil. andreia.david@unimontes.br (ORCID: 0000-0002-2747-5941) / cristiane.fogaca@unimontes.br (ORCID: 0000-0002-9640-8451)

Iv Engenheira Agrônoma, Ma., Doutoranda do Programa em Ciência e Tecnologia de Sementes, Universidade Federal de Pelotas, Faculdade de Agronomia Eliseu Maciel, Av. Eliseu Maciel, 1000, CEP 96010-900, Capão do Leão (RS), Brasil. figueiredjosiane@gmail.com (ORCID: 0000-00017105-1241)

IV Engenheira Agrônoma, Ma., Universidade Estadual de Montes Claros, Av. Reinaldo Viana, 2630, Bico da Pedra, CEP 39440-000, Janaúba (MG), Brasil. kenniakarol1@hotmail.com (ORCID: 0000-0003-3123-614X) 


\section{Introdução}

O mogno africano (Khaya grandifoliola) pertence à Família das Meliaceas e tem origem em diferentes países africanos. Foi introduzido no Brasil na década de 70, com o objetivo de substituir o mogno brasileiro (Swietenia macrophylla), intensamente explorado pelo setor de madeira e atualmente sob a ameaça de extinção (TUCCI et al., 2007). No Brasil, o mogno africano está sendo indicado para plantios comerciais pelo seu alto valor econômico no comércio internacional, devido a sua beleza e a durabilidade da sua madeira e, principalmente, por apresentar desenvolvimento relativamente rápido (CASTRO et al., 2008).

O estudo de espécies florestais, em análise de sementes, tem merecido atenção no meio científico, visando à obtenção de informações, atualmente escassas, que expressem a qualidade fisiológica das sementes, tanto para sua preservação como para a utilização dessas espécies vegetais com os mais variados interesses. No entanto, poucas espécies florestais estão incluídas nas Regras para Análise de Sementes - RAS (BRASIL, 2009), o que dificulta a realização do teste de germinação.

A semente apresenta atributos como organismo biológico e insumo agrícola, sendo de grande importância, pois conduz ao campo as características genéticas responsáveis ao crescimento das plantas e, ao estabelecimento do estande desejado, gerando a base para a produção rentável (MARCOS FILHO, 2015). Assim, se faz necessário a utilização de sementes de boa qualidade, visto que a escolha das sementes na produção de mudas é um dos principais fatores a ser considerado na implantação da cultura.

A qualidade da semente é rotineiramente avaliada em laboratórios através do teste de germinação, o qual é considerado um dos mais importantes estádios do biociclo vegetal, caracterizado pela retomada das atividades anabólicas e catabólicas, incluindo a respiração, síntese de proteínas e mobilização das reservas após a absorção da água, possibilitando o crescimento do eixo embrionário, culminando com a protrusão da radícula (LOPES, 2012).

O conhecimento das condições adequadas para a germinação é de fundamental importância, principalmente pelas respostas diferenciadas que ela pode apresentar aos diversos fatores, como: água, luz, temperatura e oxigênio e ocorrências de agentes patogênicos associados ao tipo de substrato para sua germinação (CARVALHO; NAKAGAWA, 2012). A temperatura tem grande influência no processo germinativo por afetar as reações bioquímicas que determinam todo esse processo, alterando a porcentagem final de germinação e a velocidade com que ocorre (FLORIANO, 2004). Dependendo da espécie, algumas respondem bem a temperaturas constantes e outras a temperatura alternada, podendo ser favorável à germinação. Isso é decorrência das condições do ambiente no qual ocorre oscilações de temperaturas diurnas e noturnas (SOARES, 2013).

Conhecer a temperatura mais adequada é fundamental para a inclusão da espécie nas RAS (BRASIL, 2009). Pois as RAS orientam a avaliação da qualidade de sementes nos laboratórios credenciados pelo Ministério da Agricultura, Pecuária e Abastecimento - MAPA.

Dessa forma, o objetivo do estudo foi avaliar o efeito de diferentes temperaturas sobre a germinação e vigor de sementes de mogno africano.

\section{Material e métodos}

O experimento foi conduzido no Laboratório de Análise de Sementes do Departamento de Ciências Agrárias da Universidade Estadual de Montes Claros (UNIMONTES), campus Janaúba (MG). Foram utilizadas sementes de mogno africano (Khaya grandifoliola), coletadas manualmente em junho de 2018 de árvores matrizes, provenientes da empresa Foco Agropecuária no município de Nova Porteirinha (MG), cujas coordenadas geográficas são: $15^{\circ} 47^{\prime} 50^{\prime \prime}$ latitude Sul e $43^{\circ} 18^{\prime} 31^{\prime \prime}$ longitude Oeste, a uma altitude média de $516 \mathrm{~m}$. Após a colheita, as sementes foram beneficiadas manualmente, homogeneizadas e acondicionadas em embalagens de papel durante sete dias em 
condições de laboratório até a realização das análises.

O delineamento experimental utilizado foi o inteiramente casualizado (DIC), em esquema fatorial $4 \times 5$, sendo quatro lotes de sementes, onde as mesmas foram coletadas de diversas matrizes, e cinco regimes de temperaturas $\left(20,25,30,35^{\circ} \mathrm{C}\right.$ constantes e $20-30^{\circ} \mathrm{C}$ alternada), com quatro repetições de 25 sementes por tratamento.

Inicialmente, as sementes dos diferentes lotes foram submetidas à determinação do teor de água pelo método da estufa a $105 \pm 3^{\circ} \mathrm{C} / 24 \mathrm{~h}$, conforme descrito nas RAS (BRASIL, 2009). Em seguida, foram realizados os seguintes testes para avaliação da qualidade fisiológica:

\section{Teste de germinação}

As sementes foram desinfetadas em solução de hipoclorito de sódio (1\% i.a. durante 1 minuto) sendo, em seguida semeadas em substrato papel germitest no sistema rolo, umedecidos com volume de água destilada ( $\mathrm{mL}$ ) equivalente a 2,5 vezes o peso seco do papel (g) (BRASIL, 2009). Os rolos contendo as sementes foram mantidos em germinadores digitais previamente regulados nos diferentes regimes de temperaturas pré-estabelecidos e mantidos sob luz constante, sendo as avaliações realizadas no vigésimo primeiro dia após a semeadura, momento em que a germinação havia estabilizado. Os resultados foram expressos em porcentagem de plântulas normais (Figura $1 \mathrm{~A})$, na qual foram consideradas normais as plântulas que apresentaram estruturas essenciais completas, bem desenvolvidas, proporcionais e sadias. Ao final do teste foi computada, também, a porcentagem de plântulas anormais (Figura 1 B).

\section{Figura 1 - Plântulas de mogno africano classificadas como normais $(A)$ e anormais $(B)$}

Figure 1 - African mahogany seedlings classified as normal (A) and abnormal (B)

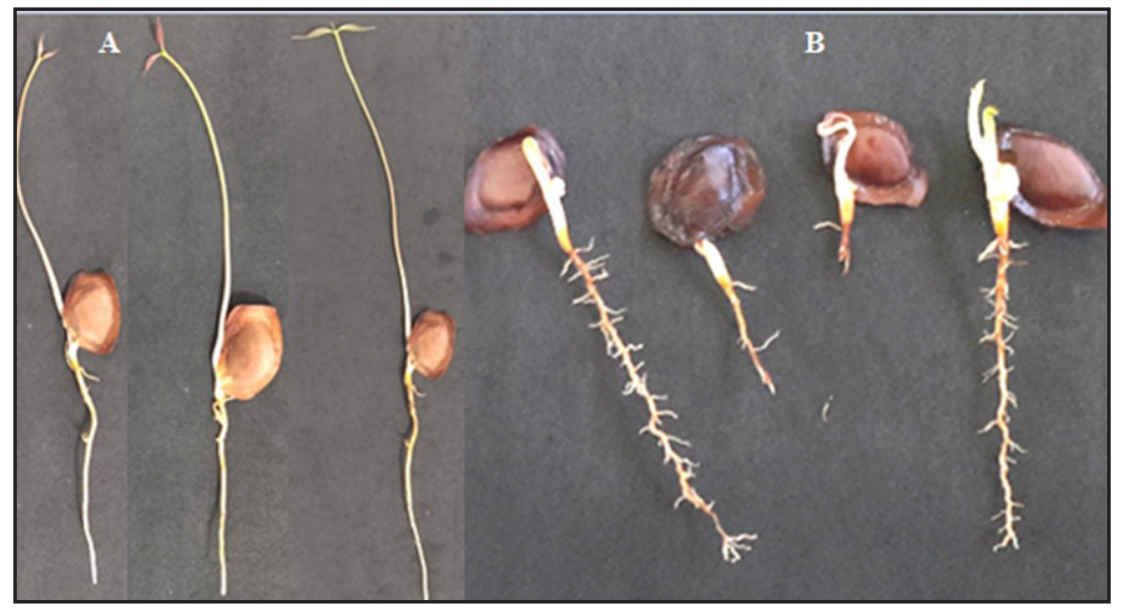

Fonte: Autores (2018)

\section{Primeira contagem de germinação}

Consistiu do registro da porcentagem de plântulas normais (Figura $1 \mathrm{~A}$ ) obtidas no sétimo dia após o início do teste de germinação.

\section{Índice de velocidade de germinação (IVG)}

O IVG foi determinado a partir de contagens diárias do número de plântulas emergidas até o vigésimo primeiro dia após a semeadura (MAGUIRE, 1962). 


\section{Comprimento de plântulas}

Foi determinado, com o auxílio de uma régua o comprimento das plântulas consideradas normais (Figura $1 \mathrm{~A}$ ), de cada repetição, e os resultados expressos em cm plântula ${ }^{-1}$.

\section{Massa fresca de plântulas}

Para a massa fresca, as plântulas normais de cada repetição foram pesadas em balança com precisão de $0,001 \mathrm{~g}$ e os resultados expressos em g plântula ${ }^{-1}$.

\section{Massa seca de plântulas}

As plântulas normais de cada repetição foram acondicionadas em sacos de papel e levados à estufa com circulação forçada de ar, a $65^{\circ} \mathrm{C}$ constante durante 72 horas. Após esse período, as amostras foram colocadas para resfriar no dessecador e novamente pesadas em balança de precisão, e os resultados médios expressos em g plântula ${ }^{-1}$.

\section{Análise estatística}

Os dados foram testados quanto à normalidade e homogeneidade, em seguida foram submetidos à análise de variância em nível de $5 \%$ de probabilidade pelo teste " $F$ ". Quando significativos os efeitos dos lotes e das temperaturas foram estudados pelo teste de Tukey a 5\% de significância.

\section{Resultados e discussão}

Os teores de água das sementes dos lotes avaliados, não diferiram entre si, com valor médio de 6,6\% de umidade, indicando que possivelmente, não houve influência do teor de água nos testes realizados.

Teores de água semelhantes entre tratamentos diversos são importantes para que os testes não sejam afetados por diferenças na atividade metabólica, velocidade de umedecimento e na intensidade de deterioração das sementes (STEINER et al., 2011).

O teor de água das sementes influencia diretamente vários aspectos de sua qualidade fisiológica, por isso a sua determinação é fundamental em testes oficiais de qualidade de lotes de sementes (SARMENTO, 2015). No presente estudo, a umidade apresentou baixa porcentagem, o que torna favorável para sementes ortodoxas como o mogno africano, uma vez que, segundo Carvalho e Nakagawa (2012), o alto teor de água pode afetar a qualidade da semente não só no período de armazenamento, mas também durante as operações de beneficiamento, dificultando o manejo e reduzindo a eficiência das máquinas utilizadas nos processos de beneficiamento.

Verificou-se efeito significativo $(\mathrm{P}<0,05)$ da interação entre os fatores temperaturas e lotes, para as variáveis germinação, primeira contagem de germinação, plântulas anormais, e massa fresca de plântulas. Houve efeito isolado de temperatura para o índice de velocidade de germinação, comprimento e massa seca de plântulas.

Em relação à germinação (Tabela 1), analisando o comportamento das plântulas de cada lote dentro de cada temperatura, observa-se que nas temperaturas de 20,30 e $35^{\circ} \mathrm{C}$, as porcentagens de germinação das sementes não diferiram entre si. Para a temperatura de $25^{\circ} \mathrm{C}$, os lotes 1 e 3 se destacaram apresentando maiores porcentagens de germinação. Quando submetidas à temperatura alternada de $20-30^{\circ} \mathrm{C}$, as sementes procedentes do lote 4 apresentaram maiores 
porcentagens de germinação, não diferindo-se estatisticamente dos lotes 1 e 3.

\section{Tabela 1 - Germinação de sementes de quatro lotes de mogno africano, em diferentes temperaturas}

Table 1 - Germination of seeds from four lots of African mahogany, at different temperatures

\begin{tabular}{lcccc}
\hline & \multicolumn{5}{c}{ Lotes } \\
\hline $\mathbf{2 0}$ & $\mathbf{1}$ & $\mathbf{2}$ & $\mathbf{3}$ & $\mathbf{4}$ \\
\cline { 2 - 5 } & $0 \mathrm{Ab}$ & $0 \mathrm{Ab}$ & $0 \mathrm{Ab}$ & $0 \mathrm{Ac}$ \\
$\mathbf{2 5}$ & $72 \mathrm{Aa}$ & $56 \mathrm{Ba}$ & $71 \mathrm{Aa}$ & $54 \mathrm{Ba}$ \\
$\mathbf{3 0}$ & $63 \mathrm{Aa}$ & $63 \mathrm{Aa}$ & $61 \mathrm{Aa}$ & $66 \mathrm{Aa}$ \\
$\mathbf{3 5}$ & $1 \mathrm{Ab}$ & $2 \mathrm{Ab}$ & $1 \mathrm{Ab}$ & $0 \mathrm{Ac}$ \\
$\mathbf{2 0 - 3 0}$ & $9 \mathrm{ABb}$ & $4 \mathrm{Bb}$ & $7 \mathrm{ABb}$ & $19 \mathrm{Ab}$ \\
\hline $\mathbf{C V}(\%)$ & & 24,37 & \\
\hline
\end{tabular}

Fonte: Autores (2018)

Em que: Médias seguidas por letras diferentes, maiúsculas na linha e minúsculas na coluna, diferem entre si pelo teste Tukey a 5\% de significância.

Estudando o efeito das temperaturas dentro de cada lote (Tabela 1), nota-se que independente do lote estudado, as temperaturas de 25 e $30^{\circ} \mathrm{C}$ proporcionaram maiores porcentagens de germinação às sementes. Esses resultados concordam com os relatados por Ferraz e Calvi (2011), os quais ressaltam que a faixa de temperatura entre 25 e $30^{\circ} \mathrm{C}$ foi indicada como a mais adequada para germinação de sementes da maioria das espécies tropicais subtropicais. Já as temperaturas constantes de 20 e $35^{\circ} \mathrm{C}$ e $20-30^{\circ} \mathrm{C}$ alternada mostraramse drásticas para todos os lotes de sementes, acarretando em decréscimos substanciais no potencial germinativo, causando danos e/ou morte do embrião, com germinação nula para a temperatura de $20^{\circ} \mathrm{C}$.

Algumas temperaturas podem inibir a germinação em sementes de determinadas espécies e comprometer as atividades enzimáticas relacionadas à mobilização de reservas, que são fundamentais durante o processo germinativo (BEWLEY et al., 2013). Temperaturas estressantes provocam danos oxidativos nas sementes, de tal forma que muitas espécies não conseguem germinar quando submetidas a temperaturas muito baixas ou muito altas (FLORES et al., 2014).

O processo de germinação das sementes envolve, inicialmente, a absorção de água e ativação dos processos bioquímicos, que resultarão na retomada do crescimento do embrião (ZIMMER, 2012). A temperatura afeta esse processo, tanto em termos de porcentagem quanto de velocidade de germinação, pois controla a absorção de água e afeta as reações bioquímicas relacionadas ao processo (CARVALHO; NAKAGAWA, 2012).

Quando as temperaturas de desenvolvimento são mantidas abaixo da ótima recomendada para germinação, a reorganização do sistema de membranas celulares pode se tornar mais lenta, influenciando no vigor das sementes (ZUCARELI et al., 2011). O atraso na germinação em resposta à baixa temperatura se deve ao alongamento da Fase II do processo germinativo, fase em que ocorre a síntese de novos RNAm (ZIMMER, 2012).

Em condições de baixas temperaturas, a embebição de sementes poderá até acontecer, porém não irá ocorrer o crescimento do embrião para a maioria das espécies (MATOS et al., 2015), podendo-se inferir, que a temperatura de $20^{\circ} \mathrm{C}$ não favoreceu a germinação das sementes 
de mogno africano. Por outro lado, Marcos Filho (2015) relata que altas temperaturas podem diminuir a porcentagem de germinação, sendo que o número de sementes que conseguem germinar cai rapidamente, em decorrência, basicamente, dos efeitos sobre a atividade de enzimas e das restrições ao acesso de oxigênio. Ainda em suas considerações, Marcos Filho (2015) ressaltou que os danos causados pelas altas temperaturas podem estar relacionados ao processo de desnaturação das proteínas e alteração nas membranas, levando a uma deterioração progressiva da semente. A germinação em regimes de temperaturas alternadas e constantes evidencia a adaptação da espécie às flutuações térmicas naturais do ambiente, o que confere maior capacidade de estabelecimento das plântulas em campo, tornando-as capazes de suportar as condições adversas do ambiente (GUEDES et al., 2010).

Para a primeira contagem de germinação (Tabela 2) verificando-se o comportamento das plântulas de cada lote dentro de cada temperatura, observa-se que nas temperaturas de 20 e $35^{\circ} \mathrm{C}$ constantes e $20-30^{\circ} \mathrm{C}$ alternada os lotes se comportaram de maneira semelhante, com germinação nula ou inexpressiva. $\mathrm{Na}$ temperatura de $25^{\circ} \mathrm{C}$ os lotes 1,2 e 4 obtiveram maiores valores, sendo que os lotes 2 e 4 não diferiram do lote 3 . Para a temperatura de $30^{\circ} \mathrm{C}$ o lote 3 mostrou-se o vigor superior aos demais lotes.

Tabela 2 - Primeira contagem de germinação de quatro lotes de sementes de mogno africano, em diferentes temperaturas

Table 2 - First germination count of four lots of African mahogany seeds at different temperatures

\begin{tabular}{lcccc}
\hline \multirow{2}{*}{$\begin{array}{c}\text { Temperaturas } \\
\left({ }^{\circ} \mathbf{C}\right)\end{array}$} & $\mathbf{1}$ & $\mathbf{2}$ & $\mathbf{3}$ & $\mathbf{4}$ \\
\cline { 2 - 5 } & $0 \mathrm{Ac}$ & $0 \mathrm{Ac}$ & $0 \mathrm{Ab}$ & $0 \mathrm{Ab}$ \\
$\mathbf{2 0}$ & $13 \mathrm{Ab}$ & $9 \mathrm{ABb}$ & $2 \mathrm{Bb}$ & $5 \mathrm{ABb}$ \\
$\mathbf{2 5}$ & $63 \mathrm{ABa}$ & $59 \mathrm{Ba}$ & $69 \mathrm{Aa}$ & $64 \mathrm{ABa}$ \\
$\mathbf{3 0}$ & $1 \mathrm{Ac}$ & $2 \mathrm{Abc}$ & $1 \mathrm{Ab}$ & $0 \mathrm{Ab}$ \\
$\mathbf{3 5}$ & $0 \mathrm{Ac}$ & $0 \mathrm{Ac}$ & $0 \mathrm{Ab}$ & $0 \mathrm{Ab}$ \\
$\mathbf{2 0 - 3 0}$ & & & 30,00 \\
\hline $\mathbf{C V}(\%)$ & & & \\
\hline
\end{tabular}

Fonte: Autores (2018)

Em que: Médias seguidas por letras diferentes, maiúsculas na linha e minúsculas na coluna, diferem entre si pelo teste Tukey a 5\% de significância.

Independentemente do lote estudado, notou-se que a incubação das sementes na temperatura de $30^{\circ} \mathrm{C}$ favoreceu a germinação na primeira contagem (Tabela 2). A primeira contagem de germinação é uma avaliação considerada como teste de vigor simples e parte do pressuposto de que as sementes mais vigorosas germinam primeiro. Nesse teste, busca-se obter respostas complementares às fornecidas pelo teste de germinação, possibilitando a obtenção de informações consistentes (OHLSON et al., 2010). 
Para as plântulas anormais (Tabela 3), comparando-se os lotes dentro de cada temperatura, observa-se que nas temperaturas de $20,25,30$ e $20-30^{\circ} \mathrm{C}$ os lotes de sementes se comportaram de maneira semelhante. No entanto, para a temperatura de $35^{\circ} \mathrm{C}$ os lotes 2,3 e 4 apresentaram menores porcentagens de plântulas anormais.

\section{Tabela 3 - Plântulas anormais oriundas de sementes de quatro lotes de mogno africano, em diferentes temperaturas}

Table 3 - Abnormal seedlings from four lots of African mahogany seeds at different temperatures

\begin{tabular}{lcccc}
\hline \multirow{2}{*}{$\begin{array}{c}\text { Temperaturas } \\
\left({ }^{\circ} \mathbf{C}\right)\end{array}$} & $\mathbf{1}$ & $\mathbf{2}$ & $\mathbf{3}$ & $\mathbf{4}$ \\
\cline { 2 - 5 } & $71 \mathrm{Aa}$ & $63 \mathrm{Aa}$ & $68 \mathrm{Aa}$ & $75 \mathrm{Aa}$ \\
$\mathbf{2 0}$ & $8 \mathrm{Ac}$ & $16 \mathrm{Ac}$ & $17 \mathrm{Ac}$ & $23 \mathrm{Ac}$ \\
$\mathbf{2 5}$ & $17 \mathrm{Ac}$ & $3 \mathrm{Ac}$ & $10 \mathrm{Ac}$ & $11 \mathrm{Ac}$ \\
$\mathbf{3 0}$ & $70 \mathrm{Aa}$ & $55 \mathrm{ABab}$ & $46 \mathrm{Bb}$ \\
$\mathbf{3 5}$ & $39 \mathrm{Ab}$ & $63 \mathrm{Aba}$ & $43 \mathrm{Ab}$ & $43 \mathrm{Ab}$ \\
$\mathbf{2 0 - 3 0}$ & & $36 \mathrm{Ab}$ & \\
\hline $\mathbf{C V ~}(\%)$ & & 25,73 & \\
\hline
\end{tabular}

Fonte: Autores (2018)

Em que: Médias seguidas por letras diferentes, maiúsculas na linha e minúsculas na coluna, diferem entre si pelo teste Tukey a 5\% de significância.

Analisando o efeito das temperaturas dentro de cada lote, observa-se que para todos os lotes analisados, as temperaturas de 25 e $30^{\circ} \mathrm{C}$ foram as que proporcionaram as sementes de mogno africano menores porcentagens de plântulas anormais, o que corrobora com os dados obtidos na germinação (Tabela 1), uma vez que quanto maior a porcentagem de germinação menor será a porcentagem de plântulas anormais.

Como princípio básico, os testes de germinação devem ser conduzidos sob condições ideais de temperatura, luz e umidade, de modo a possibilitar uma germinação uniforme, rápida e completa da amostra de sementes da espécie em questão, e possibilitar o desenvolvimento das plântulas até que possam ser classificadas como normais ou anormais (LIMA JUNIOR, 2010).

Verificando o comportamento dos lotes dentro de cada temperatura, para a massa fresca de plântulas normais (Tabela 4), nota-se que nas temperaturas de 20,35 e $20-30^{\circ} \mathrm{C}$ os lotes não diferiram entre si, em virtude de apresentarem germinação nula ou inexpressiva (Tabela 1), o que impossibilitou a aferição do acúmulo da massa da matéria fresca de plântulas normais. Contudo, na temperatura de $25^{\circ} \mathrm{C}$ o lote 3 se mostrou superior, porém não se diferindo do lote 1 . Por fim, na temperatura de $30^{\circ} \mathrm{C}$, os maiores acúmulos de massa fresca de plântulas normais de mogno africano foram verificados nos lotes 3 e 4 .

Para o efeito de temperaturas dentro de cada lote (Tabela 4), observa-se que para o lote 1 as temperaturas de 25 e $30^{\circ} \mathrm{C}$ não diferiram, proporcionando maiores acúmulos de massa fresca às plântulas normais comparativamente as demais temperaturas. Já para os lotes 2,3 e 4 , a incubação das sementes a $30^{\circ} \mathrm{C}$ proporcionou plântulas normais com maiores conteúdos de massa fresca. 


\section{Tabela 4 - Massa da matéria fresca (g) de plântulas normais, oriundas de sementes de quatro lotes de mogno africano, em diferentes temperaturas}

Table 4 - Mass of fresh matter (g) of seedlings, from four lots of African mahogany seeds, at different temperatures

\begin{tabular}{lcccc}
\hline \multirow{2}{*}{$\begin{array}{c}\text { Temperaturas } \\
\left({ }^{\circ} \mathbf{C}\right)\end{array}$} & $\mathbf{1}$ & $\mathbf{2}$ & $\mathbf{3}$ & $\mathbf{4}$ \\
\cline { 2 - 5 } $\mathbf{2 0}$ & $0,0 \mathrm{Ab}$ & $0,0 \mathrm{Ac}$ & $0,0 \mathrm{Ac}$ & $0,0 \mathrm{Ac}$ \\
$\mathbf{2 5}$ & $5,0 \mathrm{Aba}$ & $3,9 \mathrm{BCb}$ & $5,2 \mathrm{Ab}$ & $3,3 \mathrm{Cb}$ \\
$\mathbf{3 0}$ & $6,1 \mathrm{Ba}$ & $6,3 \mathrm{Ba}$ & $7,7 \mathrm{Aa}$ & $6,9 \mathrm{Aba}$ \\
$\mathbf{3 5}$ & $0,0 \mathrm{Ab}$ & $0,0 \mathrm{Ac}$ & $0,0 \mathrm{Ac}$ & $0,0 \mathrm{Ac}$ \\
$\mathbf{2 0 - 3 0}$ & $0,0 \mathrm{Ab}$ & $0,0 \mathrm{Ac}$ & $0,0 \mathrm{Ac}$ & $0,0 \mathrm{Ac}$ \\
\hline $\mathbf{C V ~}(\mathbf{\%})$ & & & & \\
\hline
\end{tabular}

Fonte: Autores (2018)

Em que: Médias seguidas por letras diferentes, maiúsculas na linha e minúsculas na coluna, diferem entre si pelo teste Tukey a 5\% de significância.

$\mathrm{Na}$ Tabela 5, temos o efeito isolado do fator temperatura para as variáveis IVG, CP e MSP. Observa-se comportamento semelhante para as três variáveis, em que a temperatura de $30^{\circ} \mathrm{C}$ possibilitou melhores resultados, sendo que a temperatura de $25^{\circ} \mathrm{C}$ resultados intermediários e as demais temperaturas proporcionaram valores inferiores. Maiores IVG indicam que as sementes germinaram mais rapidamente e de maneira uniforme, sendo, portanto, mais vigorosas.

Tabela 5 - Índice de velocidade de germinação (IVG), comprimento (CP) e massa seca (MSP) de plântulas normais, oriundas de sementes de mogno africano em diferentes temperaturas

Table 5 - Germination speed index (GSI), length (L) and dry mass (DM) of normal seedlings, from African mahogany seeds at different temperatures

\begin{tabular}{lccc}
\hline \multirow{2}{*}{$\begin{array}{c}\text { Temperaturas } \\
\left({ }^{\circ} \mathbf{C}\right)\end{array}$} & IVG & CP $(\mathbf{c m})$ & MSP $(\mathbf{g})$ \\
\cline { 2 - 4 } & $0,0 \mathrm{c}$ & $0,0 \mathrm{c}$ & $0,0 \mathrm{c}$ \\
$\mathbf{2 0}$ & $1,9 \mathrm{~b}$ & $18,0 \mathrm{~b}$ & $0,3 \mathrm{~b}$ \\
$\mathbf{2 5}$ & $2,8 \mathrm{a}$ & $23,2 \mathrm{a}$ & $0,8 \mathrm{a}$ \\
$\mathbf{3 0}$ & $0,0 \mathrm{c}$ & $0,0 \mathrm{c}$ & $0,0 \mathrm{c}$ \\
$\mathbf{3 5}$ & $0,2 \mathrm{c}$ & $0,0 \mathrm{c}$ & $0,0 \mathrm{c}$ \\
\hline $\mathbf{2 0 - 3 0}$ & 25,53 & 16,15 & 54,11 \\
\hline $\mathbf{C V}(\mathbf{\%})$ & &
\end{tabular}

Fonte: Autores (2018)

Em que: Médias seguidas de mesma letra não diferem entre si pelo teste Tukey a 5\% de probabilidade.

Em relação ao comprimento de plântulas normais, a sua determinação é realizada levando em consideração que as amostras que expressam os maiores valores são mais vigorosas. Isso ocorre devido ao fato das sementes mais vigorosas originarem plântulas com maior taxa 
de crescimento, em função da maior translocação das reservas dos tecidos de armazenamento para o crescimento do eixo embrionário (GUEDES et al., 2009). Nesse sentido, os resultados do presente estudo indicam que as temperaturas de 20,35 e $20-30^{\circ} \mathrm{C}$ prejudicaram a translocação das reservas dos tecidos de armazenamento, comprometendo o crescimento do eixo embrionário.

\section{Conclusões}

As temperaturas de 25 e $30^{\circ} \mathrm{C}$ constantes são favoráveis à germinação e ao vigor das sementes de mogno africano.

Temperaturas de 20 e $35^{\circ} \mathrm{C}$ constante e $20-30^{\circ} \mathrm{C}$ alternadas são prejudiciais ao processo germinativo das sementes de mogno africano, comprometendo o desempenho fisiológico da semente.

Nas temperaturas favoráveis a germinação, as sementes de mogno africano dos lotes 1 e 3 mostraram se com qualidade fisiológica superior aos demais.

\section{Agradecimentos}

À Coordenação de Aperfeiçoamento de Pessoal de Nível Superior (Capes); ao Conselho Nacional de Desenvolvimento Científico e Tecnológico ( $\mathrm{CNPq})$; e à Fundação de Amparo à Pesquisa do Estado de Minas Gerais (Fapemig), pelo apoio financeiro para o desenvolvimento desta pesquisa.

\section{Referências}

BEWLEY, J. D.; BRADFORD, K.J.; HILHORST, H.W.M.; NONOGAKI, H. Seeds: physiology of development, germination and dormancy. New York: Springer, 2013. 392 p.

BRASIL. Ministério da Agricultura, Pecuária e Abastecimento. Regras para análise de sementes. Secretaria de Defesa Agropecuária. Brasília, DF: MAPA/ACS, 2009. 395 p.

CARVALHO, N.M.; NAKAGAWA, J. Sementes: ciência, tecnologia e produção. 5.ed. Jaboticabal: FUNEP, 2012. 590p.

CASTRO, C. R. T.; LOURENÇO JÚNIOR, J. B.; SANTOS, N. F. A.; MONTEIRO, E. M. M.; AVIZ, M. A. B.; GARCIA, A. R. Sistema silvipastoril na Amazônia: ferramenta para elevar o desempenho produtivo de búfalos. Ciência Rural, Santa Maria, v. 38, n. 8, p. 2395-2402, 2008.

FERRAZ, I.D.K.; CALVI, G.P. Teste de germinação. In: LIMA JÚNIOR, M.J.V. (Ed.). Manual de procedimentos de análise de sementes florestais. Londrina: Abrates, 2011. p. 5.1-5.36.

FLORES, A. V. et al. Atividade enzimática durante a germinação de sementes de Melanoxylon brauna Schott sob diferentes temperaturas. Cerne, Lavras, v. 20, n. 3; p. 401-408, 2014.

FLORIANO, E.P. Germinação e dormência de sementes florestais. Santa Rosa: ANORGS, 2004. $19 \mathrm{p}$.

GUEDES, R. S.; ALVES, E.U.; GONÇALVES, E.P.; BRAGA JUNIOR, J.M.; VIANA, J.S.; COLARES, P.N.Q. Substratos e temperaturas para testes de germinação e vigor de sementes de Amburana cearensis (Allemão) a.c. Smith. Revista Árvore, Viçosa, v. 34, n. 1, p. 57-64, 2010.

GUEDES, R. S.; ALVES, E.U.; GONÇALVES, E.P.; VIANA, J.S.; MEDEIROS, M.S.; LIMA, C.R. Teste de comprimento de plântula na avaliação da qualidade fisiológica de sementes de Erythrina 
velutina Willd. Semina: Ciências Agrárias, Londrina, v. 30, n. 4, p. 793-802, 2009.

LIMA JUNIOR, M. J.V. Manual de Procedimentos para Análise de Sementes Florestais. 146p, UFAM - Manaus-Amazonas, Brasil, 2010.

LOPES, A.P. Mudanças climáticas globais e estresses abióticos em sementes e plântulas de abóbora. Dissertação (mestrado em agronomia) - Universidade do Estado da Bahia, Juazeiro-BA, p.9. 2012.

MAGUIRE, J.D. Speeds of germination-aid selection and evaluation for seedling emergence and vigor. Crop Science, Madison, v.2, p. 176-177, 1962.

MARCOS FILHO, J. Fisiologia de sementes de plantas cultivadas. 2 ed. Piracicaba: FEALQ, 2015.

MATOS, A. C. B.; BORGES, E. E. L.; SILVA, L. J. Fisiologia da germinação de sementes de Dalbergia nigra (Vell.) Allemão ex Benth. sob diferentes temperaturas e tempos de exposição. Revista Árvore, Viçosa, v. 39, n. 1, p. 115-125, 2015.

NAKAGAWA, J. Testes de vigor baseados no desempenho das plântulas. In: KRZYZANOWSKI, F. C.; VIEIRA, R. D.; FRANÇA NETO, J. B. (Ed.). Vigor de sementes: conceitos e testes. Londrina: ABRATES, 1999. p. 2.1-2.24.

OHLSON, O.C; KRZYZANOWSKI, F.C.; CAIEIRO, J.T. \& PANOBIANCO, M. Teste de envelhecimento acelerado em sementes trigo. Revista Brasileira de Sementes, Londrina, v. 32, n. 4, p. 118-124, 2010.

SARMENTO, H.G.S.; DAVID, A.M.S.S.; BARBOSA, M.G.; NOBRE, D.A.C.; AMARO, H.T.R. Determinação do teor de água em sementes de milho, feijão e pinhão-manso por métodos alternativos. Energia na Agricultura, Botucatu, v. 30, n. 3, p. 249-256, 2015.

SOARES, D.C.P. Validação de métodos para teste de germinação de sementes de espécies florestais com madeira exportada. 2013. 67f. Dissertação (Mestrado em fitotecnia) - Universidade Federal de Uberlândia, Uberlândia, 2013.

STEINER, F. OLIVEIRA, S.S.C.; MARTINS, C.C.; CRUZ, S.J.S. Comparação entre métodos para a avaliação do vigor de lotes de sementes de triticale. Ciência Rural, Santa Maria, v. 41, n. 2, p. 200-204, 2011.

TUCCI, C. A. F.; SOUZA, P. A.; VENTURIN, N.; BARROS, J. G. Calagem e adubação para a produção de mudas de mogno (Swietenia macrophylla King). Cerne, Lavras, v. 13, n. 3, p. 299-307, 2007.

ZIMMER, P.D. Fundamentos da qualidade da semente. In: PESKE, S.T.; VILLELA, F.A.; MENEGHELlO, G.E. Sementes: fundamentos científicos e tecnológicos. 3ed. rev. e ampl., Pelotas: Ed. Universitária/UFPel, 2012. p.105-160.

ZUCARELI, C.; CAVARIANI, C.; OLIVEIRA, E.A.P.; NAKAGAWA, J. Métodos e temperaturas de hidratação na qualidade fisiológica de sementes de milho. Revista Ciência Agronômica, Fortaleza, v.42, n.3, p.684-692, 2011. 